\title{
Regime de colaboração e formação docente: práticas discursiuas na produção política ProBNCC/RN
}

\author{
Régimen de colaboración y formación docente: prácticas discursivas \\ en la producción política ProBNCC / RN/Brasil
}

\section{Collaboration and teacher training regime: discursive practices in political production ProBNCC / RN/Brazil}

\section{Marcia Betania de Oliveira'}

Universidade do Estado do Rio Grande do Norte, Faculdade de Educação, Professora adjunta.

https://orcid.org/0000-0001-7881-1565

Resumo: Neste escopo abordamos processos políticos em torno do ProBNCC no estado do Rio Grande do Norte, com destaques para percursos vivenciados pelo regime de colaboração estado/municípios na organização curricular e na formação de professores, necessário à considerada implementação da BNCC. Apresentamos dados de uma pesquisa qualitativa, de caráter exploratório-descritivo, desenvolvida com base na leitura de documentos considerados norteadores da produção curricular do estado do Rio Grande do Norte (2017-2019), produzidos pela Secretaria de Estado da Educação (SEEC/ RN), bem como de documentos produzidos pelo MEC em torno do ProBNCC. Apontamos fragmentos de conversas com representante da $12^{\circ}$ DIREC, parte dessa Secretaria, bem como, com representantes da SEME/Mossoró/RN. DIREC e SEME, se apresentam como lócus de discussão, planejamento e pretensa implementação da BNCC, possibilitando a proposta de articulação entre estado e municípios no processo político ProBNCC. A investigação visa a interpretar produções políticas de significação produzida nesse âmbito discursivo a partir da perspectiva discursiva com base no ciclo de políticas e na teoria do Discurso de Ernesto Laclau. Compreendemos produção curricular e formação docente como espaços de disputa e negociações, articuladas na ideia do regime de colaboração entre estado e municípios envolvidos nessa produção política. Como resultado, consideramos que, apesar da tendência regulatória e prescritiva, a partir do ProBNCC/RN, secretarias de educação e escolas desenvolvem sistemáticas próprias da produção curricular e de formação docente.

Palavras-chave: ProBNCC/RN. Regime de colaboração. Formação docente. Produção curricular. Práticas discursivas.

Doutora em Educação pela Universidade Estadual do Rio de Janeiro; Mestre em Educação pela Universidade Federal do Rio Grande do Norte. 
Abstract: This scope addresses political processes around the ProBNCC in the state of Rio Grande do Norte/Brazil, with highlights for paths experienced by the state/municipal collaboration regime in curriculum organization and teacher training, necessary for the considered implementation of the BNCC. It is a qualitative research, of an exploratory-descriptive character, developed based on the reading of the documents considered to guide the curricular production of the state of Rio Grande do Norte (20172019), produced by the Secretary of State for Education (SEEC/RN/BR), as well as documents produced by the MEC around the ProBNCC. It points out fragments of conversations with the representative of the 12th DIREC, part of this Secretariat, as well as with representatives of SEME / Mossoró / RN. DIREC and SEME, present themselves as the locus of discussion, planning and alleged implementation of the BNCC, enabling the proposal of articulation between state and municipalities in the ProBNCC political process. It aims to interpret political productions of meaning produced in this discursive scope from the discursive from the discursive perspective based on the policy cycle and the theory of Discourse by Ernesto Laclau. It comprises curriculum production and teacher training as spaces for dispute and negotiations, articulated in the idea of the collaboration regime between the state and municipalities involved in this political production. As a result, it is possible to perceive that, despite the regulatory and prescriptive tendency, from the ProBNCC / RN, education departments and schools develop systems specific to curricular production and teacher training.

Keywords: ProBNCC/RN/Brazil. Collaboration regime. Teacher training. Curricular production. Discursive practices.

Resumen: En este ámbito, abordamos los procesos políticos en torno al ProBNCC en el estado de Rio Grande do Norte/Brasil, con aspectos destacados de los caminos experimentados por el régimen de colaboración estatal/municipal en la organización del currículo y la capacitación docente, necesarios para la implementación considerada del BNCC. Presentamos datos de una investigación cualitativa, de carácter exploratorio-descriptivo, desarrollada en base a la lectura de los documentos considerados para guiar la producción curricular del estado de Rio Grande do Norte (2017-2019), producida por la Secretaría de Estado de Educación (SEEC/RN), así como documentos producidos por el MEC en torno al ProBNCC. Señalamos fragmentos de conversaciones con un representante de la $12^{\circ}$ DIREC, parte de esta Secretaría, así como con representantes de SEME / Mossoró / RN. DIREC y SEME, se presentan como el lugar de discusión, planificación y supuesta implementación de BNCC, permitiendo la propuesta de articulación entre el estado y los municipios en el proceso político ProBNCC. La investigación tiene como objetivo interpretar las producciones políticas del significado producido en este ámbito discursivo desde la perspectiva discursiva basada en el ciclo de políticas y la teoría del discurso de Ernesto Laclau. Entendemos la producción curricular y la capacitación docente como espacios para disputas y negociaciones, articulados en la idea del régimen de colaboración entre el estado y los municipios involucrados en esta producción política. Como resultado, consideramos que a pesar de la tendencia normativa y prescriptiva, desde el ProBNCC / RN, los departamentos de educación y las escuelas desarrollan sistemas específicos para la producción curricular y la capacitación docente. 
Palabras clave: ProBNCC/RN/Brasil. Régimen de colaboración. Formación del profesorado. Producción curricular. Prácticas discursivas.

Recebido em 6 de março de 2020

Aceito em 16 de agosto de 2020

Publicado em 24 de setembro de 2020

\section{INTRODUÇÃO}

0 Programa de Apoio à Implementação da Base Nacional Comum Curricular (ProBNCC) foi lançado pelo Ministério da Educação, em 2019, com vista a auxiliar estados, municípios e o Distrito Federal na elaboração e implementação de seus currículos alinhados à Base Nacional Comum Curricular (BNCC). Nesse programa, destacamos a centralidade dada d̀ produção curricular e à formação de professores, definida a partir de apoio técnico oferecido pelo MEC, para a elaboração de propostas curriculares, seja das secretarias de educação seja das escolas, e para a revisão dos projetos pedagógicos das escolas. A proposta de "implementação" da BNCC está diretamente associada à formação docente.

Ao apresentar a Base Nacional Comum para a Formação de Professores da Educação Básica ao Conselho Nacional de Educação (CNE), em dezembro de 2018, a chamada pública do Ministério da Educação, destaca que a "Formação de professores será norteada pelas regras da BNCC." (BRASLL, 2018). Elaborada com o objetivo de "orientar uma linguagem comum sobre o que se espera da formação de professores, a fim de revisar as diretrizes dos cursos de pedagogia e das licenciaturas para que tenham foco na prática da sala de aula e estejam alinhadas à BNCC", espera-se, conforme afirmação do então ministro da educação Rossieli Soares, "dizer ao Brasil o que é ser um bom professor, quais são as competências e habilidades necessárias para ele, especialmente com foco na prática pedagógica, numa visão mais próxima da sala de aula." (BRASIL, 2018).

0 estado do Rio Grande do Norte, que vivencia um momento considerado histórico na construção de um documento curricular desde 2018 (RIO GRANDE DO NORTE, 2018b), aderiu ao ProBNCC, por meio da Secretaria de Educação do Estado (SEEC/RN), com vista à articulação com os municípios potiguares para a construção de uma proposta curricular que se propõe a servir de referência para as escolas públicas e privadas desse estado, a fim de estabelecer os conteúdos mínimos que deverão ser ensinados em todas as escolas, públicas e privadas. Para tanto, vem promovendo articulações em torno da formação de profissionais da educação, dentre eles técnico-pedagógicos das secretarias estaduais e municipais de 
ensino, bem como, equipes gestoras das escolas, coordenadores/supervisores pedagógicos e professores.

Neste escopo abordamos, portanto, processos políticos em torno do ProBNCC no estado do Rio Grande do Norte, com destaques para percursos vivenciados pelo regime de colaboração estado/municípios na formação de professores, tido como necessário à considerada implementação da BNCC. Compreendemos tais processos como produção política, entendendo o ProBNCC como parte dessa produção, no contexto de influência, com tendência regulatória e prescritiva para a formação docente e para a produção curricular. 0 contexto de influência, parte do ciclo de políticas apontado por Ball e Bowe (1992), é entendido como espaços "onde normalmente as políticas públicas são iniciadas e os discursos políticos são construídos. [...] Atuam nesse contexto as redes sociais dentro e em torno de partidos políticos, do governo e do processo legislativo." (MAINARDES, 2006, p. 52). É nesse contexto "que os conceitos adquirem legitimidade e formam um discurso de base para a política" (MAINARDES, 2006, p. 52).

Nessa perspectiva, entendemos que discursos em torno da ideia de operacionalização do regime de colaboração entre entes federados adquire legitimidade que tende a homogeneizar processos formativos docentes e produções curriculares de estados e seus municípios.

Metodologicamente, apresentamos dados de uma pesquisa qualitativa, de caráter exploratório-descritivo, desenvolvida com base na leitura dos documentos considerados norteadores da produção curricular do estado do Rio Grande do Norte (2017-2019), produzidos pela Secretaria de Estado da Educação (SEEC/RN), bem como de documentos produzidos pelo MEC em torno do ProBNCC. Destacamos, ainda, fragmentos de conversas com representante da $12^{a}$ Diretoria Regional de Educação (DIREC), parte dessa Secretaria, bem como com representantes da Secretaria Municipal de Mossoró/RN la ser apresentada aqui como SEME/ Mossoró/RN). DIREC e SEME são aqui identificadas como lócus de discussão, planejamento e pretensa implementação da BNCC, possibilitando a proposta de articulação entre estado e municípios no processo político ProBNCC. Consideramos tais documentos curriculares e falas de atores sociais como produção discursiva da/na constituição política ProBNCC.

Consideramos as secretarias de educação do estado (SEEC/RN) e do município (SEME/Mossoró/RN), e a $12^{a}$ DIREC como instâncias mediadoras da/na elaboração da política em certas relações de poder, aqui representando espaços que legitimam o discurso em torno do regime de colaboração entre os entes federados. As práticas por elas desenvolvidas (como a gestão dos sistemas pela produção de diretrizes curriculares, de programas pedagógicos, de orientações para a prática docente por meio da formação docente, de orientação para a reorganização dos Projetos Político-Pedagógicos - PPPs - nas escolas, dentre outras) se organizam em torno da luta pela hegemonia. Essa luta, como espaço 
político, conforme definido por Mouffe (2011), está associada à indecidibilidade estrutural da sociedade e à necessidade de uma teoria da decisão a ser tomada nesse lugar indecidível. Ao mesmo tempo em que é elaborada nos encontros formativos promovidos pela SEEC/RN, a proposta política é vivenciada no interior da SEME/Mossoró/RN, da $12^{a}$ DIREC e das escolas. Escolas, diretorias regionais de educação e secretarias estadual e municipal de educação constituem políticas curriculares.

Nessa perspectiva, destacamos elementos do ciclo de políticas, em especial do contexto da prática, como importantes na compreensão da atuação dos sujeitos para a interpretação das políticas curriculares e de formação docente. Também, visamos a interpretar produções políticas de significação produzida nesse âmbito discursivo a partir da Teoria do Discurso (TD) de Ernesto Laclau (2011), em perspectiva pós-estrutural. Entendemos a viabilidade de articulação entre o ciclo de políticas e a teoria do discurso como perspectivas teórico-metodológicas de análise. A TD é definida como uma teoria política, devendo "ser lida como uma empreitada intelectual no sentido de fornecer ferramentas teóricas para a explicação de fenômenos sociopolíticos," em que discurso possui centralidade explicativa para esse projeto teórico (MENDONÇA, 2012, p. 205). Discurso é, portanto, "[...] uma totalidade relacional de significantes que limitam a significação das práticas e que, quando articulados hegemonicamente, constituem uma formação discursiva. E esta é um conjunto de discursos articulados, por meio de diferentes práticas hegemônicas." (LACLAU, 2011, p. 9-10). Assim, "entender uma formação discursiva significa entender um processo hegemônico: como são definidos os termos do debate político, quais agendas e ações são priorizadas, que instituições, diretrizes e normas são criadas." (LACLAU, 2011, p. 9-10).

Concordamos com Lopes (2013) que a abordagem pós-estrutural se apresenta produtiva para a compreensão de políticas de currículo. Essa autora (LOPES, 2013, p. 18) destaca que com a incorporação de registros teóricos pós-críticos, como o pós-estruturalismo, é desestabilizada "a noção de currículo como um conhecimento selecionado [...], em nome de um projeto de transformação social e de formação de sujeitos." Lopes afirma ainda, que, com o questionamento ao sujeito centrado, com identidades fixas, são desestabilizados os projetos curriculares que têm por propósito "formar uma dada identidade no aluno ou operar com uma identidade docente pré-estabelecida. Também são desestabilizados os projetos de formação de um sujeito emancipado e consciente, capaz de dirigir a transformação social." (LOPES, 2013, p. १८).

Compreendemos produção curricular e formação docente como espaços de disputas e negociações, articuladas na ideia do regime de colaboração entre estado e municípios envolvidos nessa produção política, parte da agenda atualmente priorizada. Entendemos a política curricular como um fluxo de influências de sujeitos e grupos sociais, 
considerando processos de mediação, tradução ou recontextualização aos quais as políticas estão submetidas.

Organizamos o texto em cinco sessões, a contar desta seção introdutória. $\mathrm{Na}$ segunda sessão apontamos elementos possíveis de considerar o ProBNCC como política regulatória e prescritiva de alinhamento dos currículos das secretarias de educação e escolas à BNCC, com centralidade da produção curricular e da formação docente. Posteriormente, apresentamos partes do processo de produção curricular do Rio Grande do Norte discursivamente articulado ao ProBNCC, destacando a proposta pedagógica e sentidos de currículo no Documento curricular do Rio Grande do Norte para a educação básica e tentativas de regulação curricular e da formação docente enquanto produções discursivas. Na parte empírica da investigação, apontamos fragmentos de falas de atores sociais envolvidos nos processos de formação docente e produção curricular em torno do ProBNCC no município de Mossoró/RN, com significações dessa produção no RN. Por fim, consideramos que, apesar da tendência regulatória e prescritiva, a partir do ProBNCC/RN, secretarias de educação e escolas desenvolvem sistemáticas próprias da produção curricular e de formação docente.

\section{O PROGRAMA DE APOIO À IMPLEMENTAÇÃO DA BASE NACIONAL COMUM CURRICULAR (PROBNCC)}

Instituído inicialmente pela Portaria MEC ( $n^{\circ} 331 / 2018$ ), o ProBNCC objetiva apoiar as Secretarias Estaduais e Distrital de Educação (SEDUC) e as Secretarias Municipais de Educação (SME) "no processo de revisão ou elaboração e implementação de seus currículos alinhados à BNCC, em regime de colaboração entre estados, Distrito Federal e municípios" (BRASIL, 2019a, p. 4). Posteriormente, essa portaria foi alterada (pela Portaria MEC n 756/2019) para inserir aspectos específicos da implementação da BNCC para o Ensino Médio.

Participam da criação desse programa o Ministério da Educação (MEC), o Conselho Nacional de Secretários de Educação (CONSED) e União Nacional dos Dirigentes Municipais de Educação (UNDIME), que formam o Comitê Nacional de Implementação da BNCC, com o apoio da Sociedade Civil (por meio de Organizações), e das representações institucionais dos Conselhos Nacionais, Estaduais e Municipais (Conselho Nacional de Educação - CNE, Fórum Nacional dos Conselhos Estaduais de Educação - FNCE e União Nacional dos Conselhos Municipais de Educação - UNCME).

Com participação mediante assinatura do Termo de Adesão pelo Secretário Estadual ou Distrital de Educação e pelo Presidente da Seccional da UNDIME do Estado, as unidades federativas que aderiram ao ProBNCC se comprometem a realizar formações 
continuadas (pretendidas) de qualidade para professores da Educação Infantil e do Ensino Fundamental, atendendo às premissas definidas no Guia de Implementação da BNCC e com um regime de colaboração bem estabelecido.

De acordo com o documento (BRASIL, 2019a, p. 4, grifo nosso), as unidades federativas que aderiram ao ProBNCC, contam com os seguintes apoios:

\begin{abstract}
1. Assistência financeira, via Plano de Ações Articuladas - PAR às Seduc, com vistas a assegurar: (i) a qualidade técnica na construção do documento curricular em regime de colaboração entre estados, Distrito Federal e municípios para toda a Educação Básica, e (ii) a implementação dos currículos elaborados à luz da BNCC; 2. Formação oferecida pelo MEC para equipes de currículo e gestão do Programa nos estados; 3. Assistência técnica que contempla: (i) pagamento de bolsas de formação para os professores da equipe ProBNCC, via FNDE (ii) contratação de analistas de gestão, (iii) equipe alocada no MEC para o apoio na gestão nacional do Programa, (iv) material de apoio, e (v) plataforma digital para apoiar a (re)elaboração do currículo e as consultas públicas.
\end{abstract}

Ainda, para o Ensino Médio, faz-se necessário que tais formações elaborem os itinerários formativos "de forma que seja considerada 'interessante' para os estudantes e que a rede seja capaz de oferecer, e incluir nos currículos orientações aos professores de como ensinar aos alunos as competências gerais da BNCC de maneira prática." (BRASIL, 2019a, p. 5, grifo do autor).

Nessa perspectiva, há uma aposta que o regime de colaboração promova o apoio do estado aos municípios na construção de documentos curriculares com vista à implementação dos currículos à BNCC, tendo como base processos formativos para docentes e equipe gestora das secretarias de educação e das escolas. Tal perspectiva parece desconsiderar que o contexto da prática produz efeitos que desestabilizariam discursos reguladores, centralizados e prescritivos, possivelmente advindos desse regime de colaboração.

Destacamos, nesse processo, tentativas de regulação das práticas para a considerada implementação da BNCC, em especial, por meio de processos formativos docentes. Como sempre tem acontecido, em especial ao longo das últimas décadas, nas agendas políticas de currículo no Brasil, há uma produção discursiva em torno da ação e da formação docentes. Produzir currículo está diretamente associado à formar professores, e, mais recentemente à formar gestores escolares, em uma lógica em que geralmente se considera que esses sejam/estejam "mal formados" e que, portanto, não dão conta de práticas curriculares consideradas satisfatórias ou exitosas de forma a contribuir com a qualidade da educação básica. 
Vale considerar que a pleiteada qualidade da educação se faz presente na articulação discursiva da BNCC, em torno da definição curricular para a educação básica, encontrando espaço para também definir o currículo da formação docente, com centralidade na docência, onde a responsabilidade pelo sucesso das reformas curriculares, sua concretização e êxito são sempre atribuídas ao professor (DIAS, 2016).

Frangela e Dias (2018), ao abordarem sentidos de docência na BNCC, considerando seus efeitos para o currículo da educação básica e da formação/atuação de professores, destacam que a questão da docência atravessa o conteúdo da BNCC de diversos modos: “seja porque a BNCC pretende ser um 'guia' orientador do currículo a ser desenvolvido pelos professores em sala de aula, seja pelos discursos que produz em torno do papel da docência na sua relação com o currículo." (FRANGELA; DIAS, 2018, p. 11, grifo do autor).

A formação docente se apresenta, então, revestida na proposta ProBNCC, endossada pelo CONSED e pela UNDIME, a ser assumida pelas Secretarias estaduais e municipais de Educação, quase sempre com ênfase em aspectos metodológicas da prática docente. Tais comunidades, aqui consideradas como partes constituintes do regime de colaboração, parecem desconsiderar, entretanto, a imprevisibilidade da ação docente em contextos reais, permeada pela provisoriedade e pelas contingências.

Ademais, embora o texto da BNCC trabalhe com a assertiva de que a proposta da base é a de não ser currículo, a criação do ProBNCC aponta direcionamentos claros na perspectiva de uma produção curricular que tende a minimizar conhecimento ao rol de campos de experiências previamente definidos para a educação infantil, e ao rol de competências para o ensino fundamental. Quanto aos itinerários formativos, considerados o diferencial na proposta para o Ensino Médio como potencial do protagonismo juvenil, há que se considerar que nem sempre o que é de "interesse" dos estudantes é compatível com a oferta da rede estadual de ensino e de cada escola em particular.

\section{A PRODUÇÃO CURRICULAR NO RIO GRANDE DO NORTE E O PROCESSO PROBNCC}

0 Estado do Rio Grande do Norte vivenciou em 2018, um momento considerado histórico na construção de um Documento curricular elaborado em parceria, entre os entes federados e com a participação de educadores. A União dos Dirigentes Municipais de Educação do Rio Grande do Norte (UNDIME/RN) e o Conselho Nacional de Secretários de Educação (CONSED/RN) firmaram em abril de 2019, pela primeira vez, o regime de colaboração com objetivos da construção do referido documento (POPULAÇÃO..., 2018). 
É creditado que o Documento sirva de referência para as escolas públicas e privadas do Rio Grande do Norte, a fim de estabelecer os conteúdos mínimos que deverão ser ensinados em todas as escolas do estado. De acordo com site (POPULAÇÃO..., 2018), "[...] isso influenciará na vida de 146.025 alunos da Educação infantil e 475.645 alunos do ensino fundamental, além de seus professores e a comunidade escolar onde elas vivem", dentre estudantes das escolas públicas e privadas, nos 167 municípios do RN.

Por meio de consulta pública ao Documento Curricular, os educadores do RN foram convidados a contribuir com esse documento, fase considerada como "um dos primeiros passos para a consolidação de um currículo que atenda às necessidades e as realidades de hoje e do futuro dos estudantes potiguares." (POPULAÇÃ0..., 2018). Após o término da Consulta Pública, a equipe de currículo passou a consolidar as contribuições e apresentar em novos Seminários Regionais. Após essa etapa, o Documento Curricular do RN aguarda envio ao Conselho Estadual de Educação para apreciação e posterior socialização do documento final no Seminário Estadual.

Em uma carta de apresentação endereçada aos professores e professoras, - Documento curricular do Estado do Rio Grande do Norte para a educação infantil (RIO GRANDE DO NORTE, 2018a) aponta para o ano de 2018 o desafio de consolidar, em regime de colaboração Estado-Municípios, um documento curricular de referência para as escolas do Rio Grande do Norte em consonância com a Base Nacional Comum Curricular (BNCC). Aqui, é possivel perceber tentativas de controle com vista à produção de documentos centralizados e prescritivos, comum ao estado do RN e seus municípios.

É destacado que o Estado do RN e alguns municípios potiguares se uniram para a considerada melhoria da aprendizagem dos estudantes do Rio Grande do Norte, na construção de um documento curricular "que estabelecesse aquilo que o estudante deve aprender para se desenvolver" com vista a possibilitar "condições de igualdade e equidade quanto ao desenvolvimento humano integral de crianças, adolescentes e jovens de todas as redes de ensino do Estado" (RIO GRANDE DO NORTE, 2018b, p. 7).

Para tanto, instituiu-se a Comissão Estadual destinada à implementação da Base Nacional Comum Curricular no Estado do Rio Grande do Norte (BNCC/RN) em relação à Educação Infantil e ao Ensino Fundamental, por meio da Portaria SEEC/GS n. 141/2018, sob presidência da Secretária de Estado da Educação e da Cultura do Rio Grande do Norte e representações da Undime e da União Nacional dos Conselhos Municipais de Educação (UNCME), com o compromisso de estabelecer e cumprir as premissas do regime de colaboração. 0 Termo de Intenção de Colaboração para construção do Documento Curricular do Estado obteve a adesão total dos 167 municípios e firmou, entre o Estado e os Municípios, o compromisso com a garantia das aprendizagens dos estudantes de todas as redes de ensino do território potiguar. 
Esse Termo de Intenção de Colaboração sela a proposta do regime de colaboração com vista à construção de um documento referência para o estado do RN e seus municípios, via currículo instituído, que indica a pretensa garantia de aprendizagem de todos os estudantes potiguares. Uma tentativa de controle da produção da política curricular e da formação docente que parece desconsiderar a constituição dessas políticas por meio da ação dos sujeitos. De acordo com Lopes e Macedo (2011, p. 232),

a tarefa de tornar um currículo instituinte envolve desconstruir os discursos que visam a controlar a proliferação de sentidos", tratando-se de "um movimento no sentido da desconstrução de hegemonias [...] com o objetivo de impedir que se fortaleçam de tal maneira que torne impossivel questionálas.

De acordo com informações disponibilizadas (RIO GRANDE DO NORTE, 2018a), a construção do referido documento para a Educação Infantil e para o Ensino Fundamental envolveu, por meio de um trabalho colaborativo, articuladores dos diversos segmentos das redes estadual, municipais e privada e os Conselhos Estadual e Municipais de Educação, dentre outros colaboradores. Configurou-se o que se considerou um processo democrático em regime de colaboração entre as redes estadual e municipais para a construção de um currículo atrelado à realidade potiguar. Há destaques que apontam (RIO GRANDE DO NORTE, 2018a, p. 9) para a mobilização de escolas, as quais puderam contribuir significativamente na sua construção; além da participação de professores e agentes da sociedade civil, por meio de mais de 15 mil acessos à consulta pública on-line. Há registros, ainda, de que as observações e sugestões apresentadas por meio da consulta pública foram categorizadas e sistematizadas, aperfeiçoando-se o texto original.

No caso do Ensino Médio, tal construção decorreu da articulação da Subcoordenadoria de Ensino Médio (SUEM) da SEEC/RN com as Diretorias Regionais de Educação e Cultura (DIRECs) na promoção de seminários de discussão e aprimoramento do Documento Curricular, entre outras medidas para a escuta de professores e outros profissionais da rede estadual, bem como de especialistas contratados (RIO GRANDE DO NORTE, 2018a, p. 9).

É apontado que o documento regulamenta quais são as aprendizagens essenciais a serem trabalhadas nas escolas, que os professores devem implementar as práticas a partir de 2020 (MAIS DE ML..., 2019) e que os profissionais envolvidos "terão a missão de socializar o conteúdo com os professores do seu território." No caso do RN, os processos formativos aconteceram de forma presencial e à distância, durante os meses de agosto a dezembro de 2019, em quatro cidades polos: Natal, Caicó, Mossoró e Pau dos Ferros.

De acordo com o presidente da UNDIME no RN, a implementação do Documento Curricular apresenta-se como "uma oportunidade ímpar para a construção de uma política 
de Estado de formação continuada atrelada a demais ações do órgão central que promova o aprimoramento da atuação dos professores em sala de aula com vistas a impactar positivamente o processo educativo dos estudantes." (MAIS DE MLL..., 2019). Para ele, as formações presenciais são defendidas como de "papel fundamental para uma implementação curricular que chegue efetivamente às salas de aula", sendo possível "proporcionar aos profissionais da educação de diferentes municípios o compartilhamento de boas práticas e desafios, valorizando as práticas do território, bem como contribuindo para o aprimoramento do trabalho na sala de aula." (MAIS DE MLL..., 2019).

A ideia de um amplo campo de abrangência do que se considera como possíveis efeitos dessa ação/projeção curricular no estado do Rio Grande do Norte nos remete à noção de universalização. Laclau (2011, p. 81) aponta que a questão da relação entre universalismo e particularismo ocupa lugar central na agenda política e teórica atual. Contribuindo com essa discussão, Oliveira (2017) destaca, a partir da teoria do discurso, o quanto considera produtivas discussões em torno da relação universal/particular para pensar discursos produzidos quanto à (des) necessidade de uma base curricular comum a todos.

Em seu texto "por um currículo sem fundamento", Lopes (2015, p. 450) destaca haver uma "unidade em relação à defesa de uma base curricular nacional comum, seu vínculo com a qualidade da educação e a solução de (grande) parte dos problemas educacionais, bem como aos esforços realizados para garantir essa base", como no caso do ProBNCC. Essa autora denota (LOPES, 2015, p. 455) sua preocupação em como a conexão 'padrões curriculares/melhoria de qualidade da educação', à qual acrescentamos 'formação docente', encontra respaldo "em nossos discursos pedagógicos, em nossas bandeiras de luta, e hoje se desenvolve em torno da necessidade de se constituir uma base curricular nacional."

\subsection{PROPOSTA PEDAGÓGICA E SENTIDOS DE CURRÍCULO NO DOCUMENTO CURRICULAR DO RIO GRANDE DO NORTE PARA A EDUCAÇÃO BÁSICA}

Sob a coordenação da Coordenadoria de Desenvolvimento Escolar, da Secretaria de Estado da Educação (CODESE/SEEC/RN), a organização do trabalho pedagógico (OTP) permeou as discussões sobre currículo escolar, sua construção e efetivação nas unidades de ensino, sobre avaliação da aprendizagem e formação de professores, seja para o Ensino Fundamental ou para o Ensino Médio (RIO GRANDE DO NORTE, 2018c).

Essa coordenadoria construiu, em parceria com a Fundação VUNESP, o documento Referências Básicas para a Organização do Trabalho Pedagógico (RBOTP) e o documento 
de Implantação e Implementação das Referências Básicas para a Organização do Trabalho Pedagógico, que prevê a construção/atualização dos Projetos Político-Pedagógicos (PPPs) de todas as escolas do estado do Rio Grande do Norte.

A OTP é considerada uma ação macro da SEEC/RN, que culminará nas escolas com a materialização dos PPPs, documento orientador da prática pedagógica e administrativa das unidades de ensino. Essa ação foi iniciada em março de 2018, com a sistematização e formação das equipes para condução do trabalho e configuração do Ambiente Virtual de Aprendizagem (AVA/Moodle), onde vem ocorrendo a interação entre as escolas, as Diretorias Regionais de Educação (DIREC) e a CODESE/SEEC/RN.

Vale destacar que o projeto político-pedagógico tem ganhado centralidade nos discursos educacionais desde a década de 1990, sendo apresentado como um dos instrumentos importantes na configuração da gestão democrática nas/das escolas. Nesse sentido, destacamos dados de uma investigação (OLIVEIRA; OLIVEIRA, 2019) sobre possíveis mudanças ocorridas nas escolas com a elaboração de seus projetos político-pedagógicos, apontando alguns resultados de entrevistas realizadas com gestores de escolas públicas do município de Mossoró/RN, sobre os sentidos atribuídos ao processo de construção do Projeto Político-Pedagógico, então entendido como política de currículo, a partir da compreensão de políticas de currículo para além dos limites do poder público governamental.

Entendendo políticas educacionais como produções de significações curriculares desenvolvidas em múltiplos contextos, a referida pesquisa (OLIVEIRA; OLIVEIRA, 2019) buscou romper com a dicotomia política/prática, na perspectiva de superar a compreensão da escola como local, somente, de resistência ou implementação de política. Para tanto, articulou o ciclo de políticas na compreensão do processo de elaboração do PPP, o qual se apresenta como necessário ao trabalho coletivo na escola, enquanto planejamento a médio e longo prazos, com a finalidade de construir uma identidade própria.

Retomando a questão do Documento Curricular para a Educação Básica (RI0 GRANDE DO NORTE, 2018b, p. 11-१2), destacamos os seguintes objetivos: sugerir estratégias didáticas que inspirem os projetos pedagógicos, os planejamentos e as práticas escolares, no sentido de valorizar situações mais dinâmicas, interativas, colaborativas e diversificadas na gestão do ensino e da aprendizagem; provocar reflexões nos professores, no espaço da escola, que contribuam para o aprimoramento do currículo em movimento; contribuir para que os profissionais de todas as redes de ensino compreendam a organização do trabalho pedagógico a partir do currículo por competências e o torne efetivo no planejamento escolar concretizado em uma prática pedagógica socialmente contextualizada que resulte em impactos positivos na aprendizagem dos estudantes e na melhoria da qualidade do ensino no Rio Grande do Norte. 
A construção do presente Documento Curricular foi orientada com base nos seguintes princípios, derivados do que preconizam a BNCC, as Diretrizes Curriculares Nacionais para a Educação Básica e o Plano Estadual de Educação do Rio Grande do Norte (20152025): igualdade de condições para o acesso, inclusão, permanência e sucesso na escola; liberdade de aprender, ensinar, pesquisar e divulgar a cultura, o pensamento, a arte e o saber, atendendo à pluralidade e à diversidade cultural, resgatando e respeitando as várias manifestações de cada comunidade; adoção de práticas pedagógicas que assegurem os direitos de aprendizagem dos estudantes, rompendo com estruturas fragmentadas do conhecimento; formação integral do sujeito por meio de um processo de gestão da aprendizagem ancorado em valores éticos, políticos e estéticos; valorização da experiência extraescolar e dos diferentes espaços e tempos educativos, abrangendo espaços sociais na escola e fora dela (RIO GRANDE DO NORTE, 2018b, p. 16).

Vale considerar que, ao apresentar as competências pretendidas para 0 desenvolvimento dos estudantes durante a educação básica, o documento curricular do RN acrescenta duas outras competências, além das dez previamente definidas pelo documento da BNCC. A competência de número onze diz respeito ao trabalho em relação à educação inclusiva, com o objetivo de desenvolver no estudante com necessidades especiais autonomia e participação efetiva. Já a competência doze trata das questões do meio ambiente, apontando a necessidade de respeitar todas as formas de vidas, bem como manter as condições necessárias para o equilíbrio do ecossistema (RIO GRANDE DO NORTE, 2018b).

0 Documento curricular do Estado do Rio Grande do Norte que trata especificamente da educação infantil (RIO GRANDE DO NORTE, 2018a) aborda concepções de currículo e proposta pedagógica. Destaca que um dos principais desafios para esse nível de ensino "é a construção de uma identidade "pedagógica" que rompa com a educação assistencialista, compensatória e preparatória e se distancie de práticas "escolarizantes" que desconsideram as especificidades da primeira infância." (RIO GRANDE DO NORTE, 2018a p. 56, grifo do autor).

Nessa perspectiva, o documento em pauta aponta "como os currículos para crianças pequenas vêm sendo pensados e desenvolvidos historicamente, compreendendo que este movimento pode colaborar para a construção da identidade pedagógica dos currículos em cada instituição educativa." (RIO GRANDE DO NORTE, 2018a, p. 57). Apresenta ainda, os fundamentos, principais conceitos e orientações teóricas e práticas no campo do currículo, que embasam a Proposta Curricular para Educação Infantil do Estado do Rio Grande do Norte. Currículo é entendido como movimento, como acontecimento, ao mesmo tempo que intenção, previsão, ainda que sempre provisória e lacunar frente à vida vivida nas interações e nas situações das instituições (RIO GRANDE DO NORTE, 2018a, p. 58).

Para o Ensino Fundamental, o Documento curricular do Estado do Rio Grande do Norte (RIO GRANDE DO NORTE, 2018b, p. 15) entende currículo "como conjunto integrado e 
articulado de vivências e experiências que possibilitam aos estudantes mobilizar e ampliar seus saberes em torno dos objetos de conhecimento considerados relevantes." Tal relevância gira em torno do desenvolvimento de habilidades e competências, a serem acionadas pelos estudantes "na tomada de decisões, na resolução de problemas presentes na vida cotidiana, no mundo do trabalho e no exercício pleno da cidadania." (RIO GRANDE DO NORTE, 2018a, p. 15).

Conforme definido no próprio documento (RIO GRANDE DO NORTE, 2018b, p. 15), a perspectiva de currículo adotada "põe em foco o processo de aprendizagem, entende o saber como algo falível e provisório [...], dá importância ao legado científico, cultural e artístico a ser trabalhado nas práticas educativas." Conhecimento é entendido como poder emancipador que deve ser aplicado na intervenção em realidades diversas e complexas.

0 referido documento (RIO GRANDE DO NORTE, 2018b, p. 16) aposta em um currículo que

\begin{abstract}
amplie a atitude reflexiva dos professores e demais integrantes da equipe escolar, enquanto planejadores dos ambientes de aprendizagem de crianças, adolescentes, jovens e adultos; ofereça referências teórico-metodológicas capazes de subsidiar o desenvolvimento das competências e habilidades previstas na BNCC e que, ao mesmo tempo, dialoguem intimamente com as práticas escolares cotidianas, com os contextos regionais/locais e, especialmente, com as características e demandas dos estudantes nas diferentes etapas e modalidades da Educação Básica; possa se desdobrar nas propostas pedagógicas das unidades escolares, nos planos de aula e, principalmente, no dia a dia dos espaços educativos da escola e das salas de aula.
\end{abstract}

É considerado que a escolha da abordagem didática (disciplinar, pluridisciplinar, interdisciplinar ou transdisciplinar), definida no projeto pedagógico de cada unidade escolar, caracteriza a efetivação do currículo nas práticas pedagógicas em todas as etapas. Tal escolha "deve ser reconhecida como a opção mais pertinente e viável para o desenvolvimento das competências e habilidades que compõem o conjunto das aprendizagens essenciais determinadas na BNCC", e ainda, "deve resultar do pacto estabelecido entre os profissionais da escola, os conselhos escolares e a comunidade." (RIO GRANDE DO NORTE, 2018b, p. 17).

A proposta de educação integral com vista à formação e ao desenvolvimento humano ganha centralidade na organização do Documento curricular do Estado do Rio Grande do Norte (RIO GRANDE DO NORTE, 2018b), na perspectiva de compreensão do que se convém chamar de complexidade e não linearidade desse desenvolvimento, "revelando uma visão plural, singular e integral da criança, do adolescente, do jovem e do adulto, considerando-os como sujeitos de aprendizagem respeitados em suas singularidades e diversidades." (RIO GRANDE DO NORTE, 2018b, p. १८). 
Nessa perspectiva, as escolas são chamadas ao compromisso de um olhar sensivel para o acolhimento, reconhecimento e desenvolvimento pleno de todos os estudantes e com respeito às diferenças e enfrentamento à discriminação e ao preconceito. É possível interpretar que a ação dinâmica de produção de sentidos com tendência regulatória e prescritiva, delineando um projeto de escolarização voltado para o desenvolvimento integral, agrega sentidos da organização do ensino por competências, com objetivos educacionais classificados e uma proposta desenvolvimentista de educação integral.

\subsection{PRODUÇÕES DISCURSIUAS: TENTATIUAS DE REGULAÇÃO CURRICULAR E DA FORMAÇÃO DOCENTE}

Ao abordar processos regulatórios de propostas curriculares pós-LDB $1996 \mathrm{na}$ região Nordeste, enquanto tentativas de "implementação" das reformas estabelecidas pela LDB que orientaram boa parte das políticas curriculares, em especial no governo Fernando Henrique Cardoso, Oliveira (2015) destaca o protagonismo de escolas e secretarias de educação na elaboração de propostas curriculares que se apresentam como diferenciadas localmente.

Ao estabelecer metas de avaliação, por meio de programas de intervenção pedagógica com vista a garantir o sucesso da educação e sua tão pretendida qualidade, a ação reguladora e centralizada do Estado (nesse caso, o do RN) parece pretender tornar universal, de "aplicabilidade" para a educação potiguar, políticas curriculares com características particulares. Em sua grande maioria, políticas curriculares como essas, "capacitam" (a exemplo do ProBNCC) professores, gestores e demais funcionários das secretarias de educação e das escolas para monitorar, acompanhar e fazer avaliações externas, em especial nas escolas, na perspectiva de aferição do desempenho discente rumo à qualidade pretendida.

Consideramos que o movimento em torno do ProBNCC, em especial do Estado do Rio Grande do Norte, se assemelha ao Curso de Atualização Curricular (CAC/RN), um outro exemplo de tentativa de regulação das práticas, ainda vivido nesse estado. Não necessariamente apresentado como uma proposta curricular mas como um programa de formação continuada de professores e profissionais da educação, o CAC/RN foi desenvolvido nos anos de 1997 e 1998 em todo o estado potiguar, para escolas estaduais. Promoveu estudos básicos, com professores e especialistas das então $1^{a}$ a $8^{a}$ séries do ensino fundamental, acerca dos Parâmetros Curriculares Nacionais (PCN), no contexto do processo ensino-aprendizagem da rede estadual de ensino, com vistas à futura implantação universal da organização curricular por ciclos (RIO GRANDE DO NORTE, 1998). 
Embora não se apresentando como de caráter obrigatório, o referido curso era "porém recomendável para todo o universo de professores do ensino fundamental" (RIO GRANDE DO NORTE, 1998, p. 7), uma vez que possibilitaria conteúdos e metodologias então consideradas renovadoras da prática pedagógica. Apresentava-se como uma proposta de "disseminação de novos procedimentos quanto ao planejamento e implementação do projeto pedagógico da escola, principalmente no que se relaciona à organização curricular e avaliação do processo ensino-aprendizagem e normalização do fluxo escolar." (RIO GRANDE DO NORTE, 1998, p. 11). É interessante destacar a centralidade dada tanto ao desenvolvimento do projeto político-pedagógico da escola em ambas as propostas quanto à formação docente da rede estadual de ensino.

0 estudo dos PCN (à época ainda em versão preliminar) era entendido como "estratégia privilegiada para se organizar os procedimentos curriculares, incluindo-se os temas transversais como elementos de ligação inter e transdisciplinar." (RIO GRANDE DO NORTE, 1998, p. 11). Os temas transversais apontados nos PCN se assemelham aos chamados Temas Contemporâneos Transversais (TCTs), propostos para o processo de implementação da BNCC (BRASIL, 2019b), cuja abordagem da contemporaneidade é considerada uma busca pela melhoria da aprendizagem nas escolas. De acordo com o documento base desses temas (BRASIL, 2019b), ao contextualizar o que é ensinado em sala de aula juntamente com os temas contemporâneos, "espera-se aumentar o interesse dos estudantes durante o processo e despertar a relevância desses temas no seu desenvolvimento como cidadão" (BRASIL, 2019b, p. 4), a fim de que "o estudante conclua a sua educação formal reconhecendo e aprendendo sobre os temas que são relevantes para sua atuação na sociedade" (BRASIL, 2019b, p. 4), contribuindo para a formação integral do estudante como ser humano, sendo essa uma das funções sociais da escola.

Nos casos citados, a organização curricular aponta para tentativas de implantar a proposta centralizadora definida (naquele contexto pelos PCN, atualmente pela $\mathrm{BNCC}$ ), homogeneizadora (naquele contexto, via CAC/RN, atualmente, via ProBNCC/RN), como conhecimento universalizado necessário a todos os potiguares. Tal organização nega e/ ou critica práticas curriculares anteriores como desatualizadas, na perspectiva de instituir o discurso favorável às então mudanças nas políticas educacionais, "visando à constituição de distintas identidades pedagógicas consideradas necessárias ao projeto político-social escolhido" (LOPES, 2004, p. 110).

A gestão escolar e a formação de professores e de especialistas em educação são apostas para o considerado sucesso dessas propostas curriculares, as quais deixam de considerar e de analisar demandas e contingências dessas práticas, carregadas de sentidos. 


\section{SIGNIFICADOS DA PRODUÇÃO CURRICULAR E DA FORMAÇÃO DOCENTE NO CONTEXTO DA PRÁTICA}

Nesse item, destacamos alguns elementos que possibilitam entender partes do processo de discussão em torno do ProBNCC/RN, permeada pela construção do Documento Curricular em pauta e da formação de professores. Para compreender como se deu esse processo apontamos fragmentos de uma entrevista com o representante la ser identificado como RI) da $12^{\circ}$ Diretoria Regional de Educação (DIREC), situada no município de Mossoró/RN, a qual é jurisdicionada à Secretaria de Estado da Educação do RN (SEEC/RN). Também, com duas representantes (a serem identificadas por R2 e R3) da Secretaria Municipal de Mossoró/ RN (SEME/ Mossoró/RN).

Buscamos compreender como representantes da considerada articulação entre estado e municípios (nesse caso, Mossoró/RN), técnico-pedagógicos das secretarias, supervisores e/ou coordenadores das escolas e Unidades de Educação Infantil (UEls), escolhidos como partícipes dessa investigação, operam com o discurso da formação docente e da produção curricular que identificam a proposta ProBNCC, (re) interpretando-a; como lidam com contingências loco/regionais em nome de uma proposta com pretensões universais.

Concordamos com Lopes (2012) que "produzir um documento curricular [...], desenvolver uma dada prática curricular [...], é se engajar em uma luta por hegemonia, lutar por uma dada fixação, uma dada representação", entendendo ser essa "[...] uma luta entre representações provisórias, precárias, limitadas e passíveis de serem traduzidas contingencialmente" e que, "nesse processo, podemos ainda considerar que, admitidas as traduções, há que se limitá-las e restringi-las, ou há que estimular sua multiplicação, no jogo incessante das diferenças." (LOPES, 2012, p. 712).

Como parte do percurso metodológico da investigação que proporciona a pesquisa empírica deste texto, mantivemos contato/conversa, em outubro de 2019, com o técnico-pedagógico da $12^{a}$ Diretoria Regional de Educação (DIREC). Em novembro de 2019, entrevistamos duas supervisoras Técnico-pedagógicas da Secretaria Municipal de Educação (SEME/Mossoró/RN (sendo uma responsável pela educação infantil e outra pelo ensino fundamental), na perspectiva de compreendermos o processo de discussão curricular em torno do ProBNCC/RN ali vivenciado.

Participamos, ainda, de dois encontros formativos realizados pela SEME/Mossoró/ RN, em dezembro de 2019, assim organizados: uma formação proporcionada pela equipe técnica responsável pelo ensino fundamental (nesse caso, os supervisores pedagógicos estavam em processo formativo) e outra formação, em uma Unidade de Educação Infantil, em 
que as supervisoras pedagógicas de um polo proporcionavam momentos formativos para as professoras.

Para efeito de organização deste escopo, na perspectiva de compreender partes da produção política curricular e de processos formativos docentes, via discurso de articulação entre o estado do Rio Grande do Norte e a SEME/Mossoró/RN, em torno do movimento ProBNCC, destacamos trechos de conversas com os técnico-pedagógicos da $12^{a}$ DIREC e da SEME/Mossoró/RN. Em meio às conversas, foi possível destacar alguns elementos importantes desse processo, considerando o nosso interesse em compreender sobre as principais temáticas tratadas durante os encontros formativos e possíveis divergências e/ ou conflitos então vivenciados nesses processos: a construção/reformulação dos PPPs das escolas na perspectiva de realinhamento à proposta da BNCC.

No que diz respeito à articulação entre estado e municípios potiguares, quanto ao movimento ProBNCC, o representante da $12^{a}$ DIREC (R1) destaca a organização de um curso promovido pela equipe técnico-pedagógica, então ofertado para os seus coordenadores pedagógicos (das escolas). Composto por quatro módulos, tal curso foi desenvolvido em parceria com a UNDIME, equipe de secretaria de educação, com as Diretoria Regional de Educação e Cultura (DIRECs). 0 curso foi desenvolvido de modo presencial e virtual por meio de uma plataforma em que as escolas usam para ter acesso ao curso. No período de realização desta investigação, a $12^{a}$ DIREC estava vivenciando o quarto e último módulo do curso, com a apresentação do Projeto Político-Pedagógico já finalizado.

R1 destaca, ainda, que há, para o ano de 2020, uma proposta de fomentar uma grande discussão, mais fechada, sobre a atualização dos PPPs nas escolas, a fim de que seja possível "ele lo PPP] se desencadear na prática, nas salas de aula". Tal documento é considerado como "[...] uma cadeia; temos uma referência da base que não é currículo, ele foi subsidiário da construção do documento curricular do Rio Grande do Norte que também é um documento de referência."

Quanto à essas atualizações dos PPPs nas escolas municipais em Mossoró/RN, uma das representantes da SEME destacou que foi promovida uma oficina especificamente para os supervisores escolares com tema "a BNCC e a interdisciplinaridade com o Projeto Político Pedagógico." No contexto, foram discutidos os PPPs, por escola, a partir do que cada escola já tinha definido em seus documentos. "Foram apenas quatro horas de duração; compreendemos que é pouco tempo para essa discussão, mas o importante é que eles tiveram a ideia de como iniciar e ter a oportunidade de vivenciar junto de sua equipe a finalização [dos PPPs]."

A partir da conversa com as representantes da SEME/Mossoró/RN, compreendemos que, ao contrário da SEEC/RN, a secretaria do município de Mossoró já tinha 
um documento curricular próprio, quando convidada a participar do processo de articulação com o estado do RN. Porém, naquele contexto, foi realizada uma parceria com o Estado do RN (em prol da considerada articulação estados/municípios para a implementação da BNCC), no que se se chamou de Elo de Ligação (Secretaria e escola), situação em que foi discutido o documento da BNCC.

Ao discutirmos sobre o processo formativo docente da equipe da Secretaria Municipal de Educação (SEME/Mossoró/RN), R3 destaca que a formação dos profissionais em torno do ProBNCC/RN tem acontecido, inicialmente, com as representantes técnico-pedagógicas da SEME (Mossoró/RN), que participam do encontro formativo com representantes das DIRECs/SEEC/RN. Após esse processo, a formação se dá em dois momentos formativos: um primeiro, proporcionado por elas, representantes da SEME/Mossoró/RN, do qual participam coordenadores pedagógicos da educação infantil e do ensino fundamental. São esses coordenadores que promovem o processo formativo, no segundo momento, junto aos professores nas escolas e/ou nas Unidades de Educação Infantil. A formação para os professores da educação infantil é diferenciada visto que trata de abordagem com campos temáticos, específicos da BNCC desse nível de ensino.

É interessante observar o movimento desencadeado nos processos formativos que vão da equipe da SEEC/RN, passa pela participação das representantes da SEME/ Mossoró até chegar aos professores nas escolas e/ou nas Unidades de Educação Infantil. Esse movimento parece desconstruir a lógica inicialmente proposta pelo regime de colaboração de orientar uma linguagem comum sobre o que se espera da formação de professores e da produção curricular (das secretarias de educação e das escolas) alinhada à BNCC.

A pretensa ideia de regulação e prescrição para a formação docente e para a produção curricular perde sentido no processo de ressignificação dessas políticas, atribuindolhes sentidos próprios. A ideia inicial que circula em torno da formação docente, e de suas ações em prol do alinhamento curricular à BNCC, é desmontada de forma a se adequar às condições e necessidades das secretarias de educação e das escolas.

Ao abordarem planejamento, Lopes e Macedo (2011, p. 68) destacam que "os textos são sempre ambivalentes em seu desejo de controle." Aqui associamos produção curricular e propostas formativas docentes como textos a serem lidos os quais, enquanto tal, "criam outros sentidos por intermédio da criação da desconstrução dos sentidos que eles projetam." (LOPES; MACED0, 2011, p. 68).

Uma das representantes da SEME/Mossoró/RN destaca que, no município (SEME/Mossoró/RN), foi realizado um grande encontro, juntamente com a UNDIME, no teatro municipal da cidade, que reuniu gestores, supervisores e professores das escolas. Naquele contexto os sujeitos tiveram a oportunidade de conhecer o documento curricular [da SEME]. 
"Nós trabalhamos com o que chamamos de agente de multiplicação, em que consiste em passarmos as formações para os supervisores escolares e eles repassam as informações com sua equipe." (R2, SEME/Mossoró/RN, 2019) (informação verbal). R2 destaca, ainda, que há atendimentos individualizados quando uma escola solicita a presença da equipe responsável pela formação de professores.

Questionamos como se dá a organização dos espaços e divisão dos professores, para o processo formativo. R3 afirma que formam/dividem as escolas e UEls por polos, considerando a aproximação geográfica das mesmas, para facilitar o trabalho de formação, na perspectiva de fortalecer as discussões. Consideramos interessante destacar uma fala de R2 quanto à definição de quais escolas/UEls compõem cada polo:

\begin{abstract}
Percebemos que, se fôssemos fazer a formação escola por escola, teriamos mais resistência (por parte de alguns supervisores). Então, escolhemos/agrupamos supervisores que, acreditamos, serem 'mais fortes', que apresentam mais habilidade para o trabalho de formação docente, que articulam melhor as questões propostas (R2, SEME/Mossoró/RN, 2019, grifo nosso com base na ênfase dada na fala do sujeito entrevistado) (informação verbal).
\end{abstract}

Questionamos se o material (em especial o bibliográfico) utilizado para a formação dos professores nas escolas e UEls, por polos, é o mesmo utilizado na formação dos coordenadores da SEME/Mossoró. Também, quais os critérios utilizados para a adequação (não só do material, mas também, das orientações gerais) nos processos formativos. Elas respondem que sim, com algumas adaptações, considerando principalmente o tempo definido para a formação nas escolas/UEls. A formação dos representantes da SEME/Mossoró/RN é de oito horas; e a dos supervisores, nas escolas/UEls é de quatro horas. De acordo com R2, "nós adequamos para a nossa realidade (da SME) e eles adequam para as deles (das escolas e UEls), não tirando o foco do tema central". "Mas, a essência permanece", enfatiza R3, destacando que "[...] na formação que nós recebemos tem muitas informações paralelas, como momentos de sensibilização, dinâmicas de acolhida, textos reflexivos [...] algumas dessas coisas são descartadas, muito embora a gente selecione a essência das discussões necessárias." (informação verbal).

A partir dos recortes de algumas falas dos sujeitos dessa investigação é possível destacarmos que as secretarias de educação e as escolas produzem política em torno da proposta de implementação da BNCC, atribuindo sentidos, traduzindo essa política no contexto de prática, para além do instituído no movimento ProBNCC e das tentativas de controle e regulação. Concordamos com Lopes (2019) que o currículo, e nesse caso a formação docente, precisa fazer sentido e ser construído contextualmente, atender demandas e necessidades 
que não são homogêneas. Enquanto tal, produção curricular e formação docente se apresentam como espaços de disputa e negociações, articuladas na ideia do regime de colaboração entre estado e municípios envolvidos nessa produção política.

0 fluxo de influências de sujeitos e grupos sociais nessa produção política possibilita processos de tradução aos quais as políticas estão submetidas. Lopes (2019, p. 61) destaca que é próprio de qualquer textualização, dentre elas a textualização curricular, ser submetida à interpretação, sendo realizada de forma imprevisível. "Nunca é uma interpretação completa (pura diferença), sem referência ao texto, nunca é o suposto caos do qualquer um entende o que bem quiser", visto que tradições curriculares balizam a intepretação, assim como relações de poder limitam os possíveis sentidos, limitando contextualmente a interpretação, em meio às dinâmicas contingentes.

\section{CONSIDERAÇÕES}

Neste artigo, procuramos abordar questões em torno da produção curricular e da formação de professores, no movimento que visa ao que se considera ser um alinhamento dos currículos à BNCC, por meio do ProBNCC, em secretarias de educação e escolas, com destaques para o estado do Rio Grande do Norte. 0 regime de colaboração entre estado e municípios se apresenta como um mecanismo necessário à essa organização.

A teoria do discurso, como perspectiva de análise, nos possibilitou compreender algumas questões: a noção de universalização em torno do ProBNCC, como possíveis efeitos da ação/projeção curricular no estado do Rio Grande do Norte para a proposta dos municípios potiguares; a ação dinâmica de produção de sentidos com tendência regulatória e prescritiva do Documento curricular do Estado do Rio Grande do Norte, delineando um projeto de escolarização voltado para o desenvolvimento integral, agregando sentidos da organização do ensino por competências, com objetivos educacionais classificados e uma proposta desenvolvimentista de educação integral; o movimento em torno do ProBNCC, em especial do Estado do Rio Grande do Norte, se assemelha ao Curso de Atualização Curricular (CAC/RN) um outro exemplo de tentativa de regulação das práticas, vivido no RN no final da década de 1990.

Por sua vez, os dados da pesquisa empírica apontam que os representantes das secretarias envolvidas no processo de articulação entre estado e municípios, em prol do ProBNCC desenvolvem políticas internas, provisória e contingencialmente, mobilizando os recursos que têm para tal, adaptando as situações contingenciais que demonstram suas tomadas de decisões na perspectiva de implementação da BNCC. Vale destacar alguns elementos utilizados pela equipe técnico-pedagógica da SEME/Mossoró/RN para a realização 
de seus processos formativos: a lógica de organização por polos se dá na perspectiva de que grupos (de professores e supervisores pedagógicos) considerados resistentes às mudanças propostas para reorganização/adaptação curricular; a adaptação do tempo de cada encontro formativo, reduzindo de oito horas por encontro, tempo destinado às formações proporcionadas para a equipe da SEME, para quatro horas.

Entendemos que a participação desses atores sociais na proposta em questão, assim como a produção de textos curriculares, constituem dadas representações para o currículo e para a formação docente. Nesses rearranjos, a proposta inicial trabalhada nos processo formativos com as equipes das secretarias vai sendo reinterpretada na perspectiva de reorganização dos currículos/projetos político-pedagógicos das escolas, traduzindo essa política no contexto de prática, para além do instituído no movimento ProBNCC e no documento curricular do estado do Rio Grande do Norte, e das tentativas de controle e regulação.

Quer seja com as adaptações necessárias no processo de mediação, ou com a intervenção do sistema municipal de educação, quer seja com sua capacidade política de lidar contingencialmente com as adversidades que vão surgindo, cotidianamente, os sujeitos que fazem as secretarias de educação (estadual e municipal) e as escolas vão se constituindo, se reconhecendo, como capazes de fazer política.

Entendemos, assim, ser bastante produtivo investigar questões em torno do ProBNCC, bem como, interpretações de envolvidos como totalidades discursivas, processos de hegemonização de sentidos, tomando o ciclo de políticas e a teoria do discurso como perspectivas teórico-metodológicas de análise. Por compreender as secretarias de educação e as escolas como lugar de constituição de políticas de currículo, de poder descentrado e difuso, a intenção foi interpretar subjetivações na política, destacando ambivalências de sentidos, embates na elaboração da política. Ao entender a negociação nas políticas de currículo como articulação discursiva, concordamos que diferentes demandas curriculares particulares são capazes de serem articuladas, de forma provisória e contingente.

Por fim, consideramos que, apesar da tendência regulatória e prescritiva, a partir do ProBNCC/RN, que projeta a ideia de uma proposta curricular para todo o estado do RN, secretarias/diretoria de educação e escolas desenvolvem sistemáticas próprias da produção curricular e de formação docente. Em torno do movimento ProBNCC, enquanto política instituída, é possivel perceber rumos diferenciados entre a DIREC/SEEC/RN e a SEME/Mossoró/RN, no processo de ressignificação dessa política. Seja na produção curricular, seja na formação docente, tais arenas reorganizam espaços, tempos, possibilitando constituição de sujeitos de acordo com suas demandas e necessidades, nos apontando elementos para a compreensão da provisoriedade e das contingências na produção da política em pauta. 


\section{REFERÊNCIAS}

BALL, S. J.; BOWE, R. Subject departments and the "implementation" of National Curriculum policy: an overview of the issues. Journal of Curriculum Studies, v. 24, n. 2, p. 97-115, 1992.

BRASLL. Ministério da Educação. Formação de professores será norteada pelas regras da BNCC. Brasilia, DF: MEC, 19 dez. 2018. Disponivel em: http://portal.mec.gov.br/component/content/article/211-noticias/218175739/72141-formacao-de-professores-sera-norteada-pelas-regras-da-bncc?ltemid=164. Acesso em: 2 dez. 2019.

BRASIL. Ministério da Educação. Secretaria de Educação Básica. Pró BNCC - Programa de Apoio à Implementação da Base Nacional Comum Curricular. Documento Orientador. Brasilia, DF: MEC; SEB, 2019a. Disponivel em: http://basenacionalcomum.mec.gov.br/images/implementacao/doc_orientador_probncc_2019a.pdf. Acesso: 2 dez. 2019.

BRASIL. Ministério da Educação. Secretaria de Educação Básica. Temas contemporâneos transversais na BNCC: propostas de práticas de implementação. Brasília, DF: MEC; SEB, 2019b. Disponivel em: http:// basenacionalcomum.mec.gov.br/images/implementacao/guia_pratico_temas_contemporaneos.pdf. Acesso: 20 dez. 2019.

DIAS. R. E. Políticas de currículo e avaliação para a docência no espaço lberoamericano. Revista Práxis Educativa, p. 590-604, set./dez. 2016. Disponivel em: http://www.revistas2.uepg.br/index.php/ praxiseducativa. Acesso: 20 dez. 2019.

FRANGELLA, R. C. P.; DIAS. R. E. Os sentidos de docência na BNCC. Efeitos para o currículo da educação básica e da formação/atuação de professores. Educação Unisinos, p. 7-15, jan./mar. 2018. Disponivel em: http://revistas.unisinos.br/index.php/educacao/article/view/edu.2018.221.01/60746115. Acesso: 10 dez. 2019.

LACLAU, E. Emancipação e diferença. Rio de Janeiro: EdUERJ, 2011.

LOPES, A. C. Democracia nas políticas de currículo. Cadernos de Pesquisa, v. 42, n. 147, p. 700-715, set./ dez. 2012.

LOPES, A. C. Itinerários formativos na BNCC do Ensino Médio: identificações docentes e projetos de vida juvenis. Revista Retratos da Escola, v. 13, n. 25, p. 59-75, jan./maio 2019. Disponível em: http//www. esforce.org.br. Acesso: 18. dez. 2019.

LOPES, A. C.; MACEDO, E. Teorias de currículo. São Paulo: Cortez, 2011.

LOPES, A. C. Políticas curriculares: continuidade ou mudança de rumos? Revista Brasileira de Educação, n. 26, p. 109-118, maio/ago. 2004.

LOPES, A. C. Por um currículo sem fundamento. Linhas Críticas, v. 21, n. 45, p. 445-466, maio/ago. 2015. 
LOPES, A. C. Teorias Pós-Críticas, Política e Currículo. Dossier Temático: Configurações da lnvestigação Educacional no Brasil. Educação, Sociedade \& Culturas, n. 39, p. 7-23, 2013. Disponível em: http:// www.fpce.up.pt/ciie/sites/default/files/02.AliceLopes.pdf. Acesso em: 20 nov. 2014.

MAINARDES, J. (org.). Abordagem do ciclo de políticas: uma contribuição para a análise de políticas educacionais. Educ. Soc., Campinas, v. 27, n. 94, p. 47-69, jan./abr. 2006. Disponivel em: http://www. cedes.unicamp.br. Acesso: 10 dez. 2012.

MAIS DE ML profissionais da educação do RN participam da formação continuada do Documento Curricular. União dos dirigentes municipais de Educação, 2019. Disponivel em https://rn.undime.org.br/ noticia/20-09-2019-12-14-mais-de-mil-profissionais-da-educacao-do-rn-participaram-da-formacao-continuada-do-documento-curricular. Acesso: 23 ago. 2019.

MENDONÇA, D. Antagonismo como identificação política. Revista Brasileira de Ciência Política, n. 9. p. 205-228, set./dez. 2012.

MOUFFE, C. Em torno a lo político. 1. ed. Buenos Aires: Fondo de Cultura Económica, 2011.

OLIVEIRA, M. B. de. "Mesmas oportunidades para todos": entre particularismo e universalismo, uma base nacional comum curricular. In: SEMINÁRIO INTERNACIONAL REDES EDUCATIVAS E TECNOLOGIAS, 9., 2017, Rio de Janeiro. Anais eletrônicos [...] Rio de Janeiro: UERJ, 2017. Disponivel em: http://www.seminarioredes.com.br/ixredes/adm/

trabalhos/diagramados/TR76.pdf. Acesso em: 23 ago. 2017.

OLIVEIRA, M. B. de; OLIVEIRA, F. F. A. PROJETO POLÍTICO-PEDAGÓGICO: política curricular no contexto da prática. Revista Panorâmica, v. 28, jul./dez. 2019. Disponível em http://revistas.cua.ufmt.br/revista/ index.php/revistapanoramica/article/viewFile/1060/19192259. Acesso: 5 jan. 2020.

OLIVEIRA, M. B. de. Propostas curriculares pós-LDB 1996: tentativas de regulação das práticas na região Nordeste. Texto recorte do trabalho encomendado no GT१2/ANPED, 2015.

POPULAÇÃO do RN poderá participar de consulta pública sobre documento curricular da educação Infantil e do Ensino Fundamental. União dos dirigentes municipais de Educação, 3 ago. 2018. Disponível em https://rn.undime.org.br/noticia/02-08-2018-08-17-populacao-do-rn-podera-participar-de-consulta-publica-sobre-documento-curricular-da-educacao-infantil-e-do-ensino-fundamental. Acesso em: 20 ago. 2019.

RIO GRANDE DO NORTE. Secretaria de Educação, Cultura e Desportos. Coordenadoria de Normas e Ações Pedagógicas - Coordenadoria de Recursos Humanos - Unidade Setorial de Planejamento. Manual de informações do Cursista. Natal: SECD, 1998.

RIO GRANDE DO NORTE. Secretaria da Educação e da Cultura. Documento curricular do Estado do Rio Grande do Norte: educação infantil. Natal: Offset, 2018a. 
RIO GRANDE DO NORTE. Secretaria da Educação e da Cultura. Documento curricular do Estado do Rio Grande do Norte: ensino fundamental. Natal: Offset, 2018b.

RIO GRANDE DO NORTE. Secretaria da Educação e da Cultura. Relatório de Gestão 2018. Natal: [s. n.], 2018c. Disponivel em: http://www.adcon.rn.gov.br/ACERVO/seec/DOC/DOC000000000191184.PDF. Acesso em: 16 jan. 2020.

Endereço para correspondência: Rua José Cândido Viana, n. 10, Alto de São Manoel, Mossoró, Rio Grande do Norte, Brasil; marciabetaniauern@gmail.com 


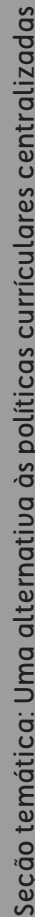

